\title{
Sektörel Reel Döviz Kuru Volatilitesinin Türk İmalat Sanayi İhracatı Üzerine Etkileri*
}

\author{
The Effects of Sectoral Real Exchange Rate Volatility on Turkish \\ Manufacturing Sector Export
}

\author{
Yrd. Doç. Dr. Esin Kılıç - Prof. Dr. Kemal Yıldırım
}

\section{Öz}

1973 yılında Bretton Woods sisteminin çöküşünün ardindan, dalgalı kur rejimi döviz kuru dalgalanmalarının dış ticarete olası negatif etkileri nedeniyle eleştirilere hedef olmuştur. Döviz kuru volatilitesinin diş ticaret üzerine etkilerini belirlemeye yönelik çok sayıda teorik ve ampirik çalışma yapılmasına rağmen, döviz kuru volatilitesinin diş ticareti etkileyip etkilemediğine, eğer etkiliyorsa bu etkinin hangi yönde olduğuna ilişkin bir görüş birliği bulunmamaktadır.

Bu çalışmada döviz kuru volatilitesinin Türkiye reel ihracat hacmine etkisi ISIC Rev. 3 sinuflandirmasina göre 22 imalat sanayi sektörü özelinde incelenmiştir. Bu amaçla, ele alınan 22 imalat sanayi için sektörel reel döviz kuru hesaplanmışve ekonometrik analiz sürecine bu kurlardan dört farkl yöntem kullamilarak elde edilen reel döviz kuru volatilitesi serileri dahil edilmiştir. 2005:Q1-2012:Q2 dönemi verileriyle panel veri analizi kullanılarak yürütülen ekonometrik analiz sonuçlarına göre, sektörel reel döviz kuru volatilitesinin sektörel ihracat hacmi üzerine etkisi pozitif ve anlamlidir.

Anahtar Kelimeler: Sektörel Reel Döviz Kuru, Volatilite, İhracat

\begin{abstract}
After the breakdown of the Bretton Woods system in 1973, floating exchange rate regime has been criticized because of the possible negative effects of exchange rate volatility on foreign trade. Although there are many theoretical and empirical studies to determine the effects of exchange rate volatility on trade, there is no consensus on whether, or which direction, exchange rate volatility affects foreign trade.
\end{abstract}

In this study, the effect of exchange rate volatility on Turkish real export volume was analyzed the case of the 22 manufacturing sectors which are classified according to the ISIC Rev. 3. To this end, sectoral real exchange rates were calculated for 22 manufacturing sectors and sectoral real exchange rate volatility series, obtained by using four different methods, were included in the econometric analysis proses. According to the results of the econometric analysis which was carried out for the period 2005:Q1-2012:Q2 and using panel data analysis, the effect of sectoral real exchange rate volatility on sectoral export volume is positive and significant.

Keywords: Sectoral Real Exchange Rate, Volatility, Export

Yrd. Doç. Dr. Esin Kılıç, Eskişehir Osmangazi Üniversitesi İ̈BF, esinkilic@ogu.edu.tr Prof. Dr. Kemal Yıldırım, Anadolu Üniversitesi İİBF, kyildirim@anadolu.edu.tr

* Bu makale Esin Kılıç’ın “Döviz Kuru ve Sektörel Reel Döviz Kuru Volatilitesinin Dış Ticaret Hacmi Üzerine Etkileri” adlı doktora tezinden üretilmiştir. 


\section{Giriş}

Ülkelerin sabit döviz kuru rejimini terk ederek esnek döviz kuru rejimini benimsemeye başladığı 1970’li yıllarda, esnek döviz kuru rejimine yönelik eleştirilerin başında, bu döviz kuru rejiminin döviz kurunun öngörülebilirliğini azaltmak suretiyle diş ticareti ve yatırımları azaltıcı bir etkisinin olabileceği gelmektedir. Esnek döviz kuru rejimini eleştiren çalışmalardan biri olan Clark (1973: 302), döviz kurunun serbestçe belirlenmesi uluslararası düzeyde ticaret yapmanın maliyetini ve bu ekonomik faaliyetlerin riskini artt1rabileceği için, dünya genelinde refah düzeyinde bir azalma olabileceğini belirtmektedir. Clark (1973), firmaların dış ticaret yapmalarının, elde etmeyi bekledikleri uzun dönem kâra bağlı olduğunu ve esnek döviz kuru rejiminin riskten kaçınma davranışı gösteren firmaların kâr beklentileri üzerinde yaratacağ dalgalanmaların, dış ticareti azaltıcı bir etki yaratabileceğini ifade etmektedir.

Döviz kuru volatilitesinin diş ticaret hacmini olumsuz etkileyebileceği yönündeki görüşlerin temelini oluşturan düşünce, firmaların döviz kuru hareketlerini dikkate alarak, bu değişikliklere göre faktör girdilerini optimal olarak ayarlayamayacaklarıdır. Ancak, firmaların üretim faktörü ya da faktörlerini döviz kuru hareketlerine göre ayarlayabilmeleri durumunda, artan değişkenlik gerçekte firma için kâr firsatları yaratabilecektir. Bu durum Canzoneri vd. (1984), Gros (1987) ve De Grauwe (1992)'de analiz edilmiștir. Üretimin döviz kuru değişmelerine göre ayarlanabildiği durumda volatilitenin diș ticaret üzerindeki net etkisi, iki zıt yönlü etkinin etkileşimi göz önünde bulundurularak değerlendirilmektedir. Birincisi, firma girdilerini hem yüksek hem de düşük satış fiyatlarına göre ayarlayabildiğinde, üretilen malın fiyatı yüksekken daha fazla mal üretebileceği için, beklenen kârlılığ döviz kuru volatilitesi yüksek olduğunda daha fazla olacaktır. İkincisi ise riskten kaçınma davranışı nedeniyle, kârlardaki yüksek değişkenlik firma üzerinde olumsuz bir etki yaratabilecek ve firmanın üretimini, dolayısıyla ihracatını azaltmasına neden olabilecektir. Burada riskten kaçınma davranışının etkisi nispeten daha düşük ise, satış fiyatı değişkenliğinin beklenen kâr üzerindeki olumlu etkisi baskın gelecek ve firma, ortalama sermaye stoku ile çıktı ve ihracat düzeyini arttırma yönünde bir karar alabilecektir.

Döviz kuru volatilitesi ile ticaret arasındaki ilişki incelenirken dikkate alınması gereken bir diğer husus ise sabit yatırımlar için harcanan sabit maliyetlerdir
(McDonald ve Siegel, 1986). Dixit (1989) ve Krugman (1989), ihracatçı firmanın yabancı piyasadan çıkmak gibi bir seçeneği olduğunu, henüz ihracatçı olmayan firmanın da gelecek dönemlerde yabancı piyasaya girme seçeneği bulunduğunu, yabancı piyasaya giriş ya da çıkış kararının ise sabit ve değişken maliyetler göz önünde bulunarak alındığını belirtmektedir. Bu nedenle yüksek döviz kuru volatilitesi ile karşılaştıkları durumda bile firmalar, piyasaya giriş ve piyasadan çıkış kararları belirli bir maliyet doğuracağı için, piyasaya giriş-piyasadan çıkış kararlarını uygulamaya koyma konusunda isteksiz olabileceklerdir. Franke (1991), reel opsiyonlar yaklaşımıyla, ihracattan beklenen para girişi yabancı piyasalara giriş ya da çıkış için katlanılması gereken maliyetlerden büyük olduğu sürece, döviz kuru volatilitesi ile ticaret hacmi arasındaki ilişkinin doğru orantılı olabileceğini ifade etmektedir. Benzer şekilde Sercu (1992)'de, ticaretten sağlanan gelirin ticaret maliyetlerini aşma olasılığ1nı arttırdığı sürece, döviz kuru volatilitesinin ticaret hacmini arttırabileceği ileri sürülmektedir.

Döviz kuru volatilitesinin ticaret hacmi üzerine etkisini genel denge modeli çerçevesinde inceleyen Viaene ve de Vries (1992), etkinin forward piyasalarının mevcut olduğu ve olmadığı durumlarda farklı olacağını ileri sürmektedir. Viaene ve de Vries (1992)'ye göre forward piyasalarının olmadığı durumda, geleneksel teorinin ileri sürdüğu gibi döviz kuru volatilitesi hem ithalatı hem de ihracatı azaltıcı bir etki gösterecektir. Forward piyasalarının varlığı durumunda ise ihracatçı ve ithalatçılar forward piyasalarında birbirine zit aktörler olduğundan döviz kuru volatilitesi ihracatı ve ithalatı farklı yönde etkilemektedir. Dolayısıyla dış ticaret hacmi döviz kuru volatilitesinden olumlu yönde etkilenebilmektedir.

Dellas ve Zilberfarb (1993), finansal riske karşı korumaya alınmamış nominal ticari sözleşmeler standart riskli varlıklar olduğu için, bu varlıkların getirisindeki risk düzeyi arttığında, diğer bir deyişle döviz kuru volatilitesi arttığında, ticaretin firmanın riskten kaçınma parametresine bağlı olarak azalabileceğini ya da artabileceğini belirtmektedir. Broll ve Eckwert (1999) ise firma riskten kaçınma davranışı gösterdiğinde, döviz kuru volatilitesinin tetiklediği yabancı piyasalardaki belirsizliklerin, gelirin beklenen faydasında bir azalışa dolayısıyla da üretim ve dış ticaret hacminde azalışa neden olduğunu; ancak büyük döviz kuru dalgalanmaları uluslararası ticaret yapmak 
için reel opsiyonu daha kârlı hale getireceğinden, firmaların üretim ve ihracatı arttırma eğiliminde olacaklarını belirtmektedir. Bu etkilerden hangisinin baskın olacağı firmanın risk karşısında göstereceği davranış ile ilgilidir ve ikincisinin baskın olması durumunda döviz kuru volatilitesinin diş ticaret hacmi üzerindeki net etkisi pozitif olacaktır.

Döviz kuru volatilitesinin dış ticaret üzerindeki etkileri araştırılırken, döviz kuru hareketlerine neden olan faktörlerin ticaret akımlarının yönü ve büyüklügü üzerindeki olası etkilerinin de göz ardı edilmemesi gerekmektedir. Bu yüzden, genel denge kapsamında makroekonomik değişkenlerin döviz kuru hareketleri ve dış ticaret üzerindeki etkilerinin birlikte ele alınmas1, döviz kuru volatilitesi ile ticaret hacmi arasındaki etkinin yönünün ortaya konulmasında yararlı olabilecektir. Bu amaçla Bacchetta ve Wincoop (2000), basit bir iki ülkeli genel denge modeli geliştirmiş ve parasal, mali ve teknolojik şoklardan kaynaklanan belirsizliklerin, sabit ve değișken döviz kuru rejiminde ticaret ve refah üzerine etkilerini araștırmıștır. Çalıșmada elde edilen bulgulara göre, döviz kuru rejimi ile dış ticaret arasında açık bir ilişki bulunmamaktadır. Döviz kuru volatilitesinin diş ticaret hacmi üzerine etkilerini teorik olarak ele alan bu çalışmalara bakıldığında, döviz kurundaki belirsizliklerin diş ticaret hacmini etkileyip etkilemediği, etkiliyorsa etkinin yönü ile ilgili tartışmalar devam etmektedir.

Döviz kuru volatilitesinin Türkiye dış ticaretine etkisini inceleyen ampirik çalışmalar ele alındığında, ekonomik analizlerin bulgularının da oldukça farklılaştığ1 görülmektedir. Bu çalışmalardan reel döviz kuru volatilitesinin Şili, Kolombiya, Peru, Filipinler, Tayland ve Türkiye'nin toplam ihracatına etkisini araştıran Caballero ve Corbo (1989), reel döviz kurunun dört çeyreklik hareketli standart sapmasını volatilite ölçüsü olarak ele almıştır. Çalışmadan elde edilen sonuçlar, incelenen ülkelerin tümünde reel döviz kuru volatilitesinin ihracat üzerinde negatif ve anlamlı etkisi olduğunu göstermiștir. Ayrıca çalıșmada döviz kuru volatilitesindeki \%5'lik bir artışın Kolombiya ihracatını $\% 2,5$ oranında, Tayland ve Türkiye ihracatını ise \%30 azalttı̆̆ı; uzun dönemde ise bu etkinin daha da arttığı belirtilmiştir. Reel döviz kuru volatilitesinin ihracat üzerine etkilerini incelerken ampirik araştırma sürecine Türkiye'yi de dahil eden bir diğer çalışma olan Doğanlar (2002)'nin ele aldığ diğer ülkeler ise Güney Kore, Endonezya, Pakistan ve Malezyadır. Çalışmada, ihracat talep modeline reel döviz kurunun dört ve sekiz dönemlik hareketli standart sapması şeklinde hesaplanan volatilite değişkeninin yanı sıra göreceli fiyatlar ve sanayileşmiş ülkelerin endüstriyel üretimi değişkenleri dahil edilmiştir. Granger eşbütünleşme testinin kullanıldığı analiz sonuçlarına göre döviz kuru volatilitesi incelenen ülkelerin ihracatını olumsuz etkilemektedir. Doğanlar (2002), Türkiye, Endonezya, Güney Kore ve Pakistan ihracatının modelde yer alan değişkenlerdeki bir değişmeden etkilendikten sonra yeniden dengeye gelmesinin uzun zaman aldığını da belirtmektedir.

Öztürk ve Acaravcı (2002), 1989:01-2002:02 dönemine ait aylık verileri kullanarak Johansen eşbütünleşme testi ve hata düzeltme modeli ile Türkiye ihracatına reel döviz kuru volatilitesinin etkisini araştırmıştır. Reel efektif döviz kuru değişim oranının hareketli ortalama yöntemiyle hesaplanmış standart sapmasının volatilite ölçüsü olarak kullanıldığ 1 çalışmada, döviz kuru volatilitesinin Türkiye ihracatına anlamlı negatif etkisinin olduğu; ancak bu etkinin kalıcı olmadığ şeklinde bulgulara ulaşılmıștır. Saatçioğlu ve Karaca (2004), döviz kuru volatilitesinin Türkiye ihracatı üzerindeki etkisinin Johansen eşbütünleşme testi ve hata düzeltme modeli kullanılarak araştırıldığı bir diğer çalışmadır. Çalışmada döviz kuru volatilitesi, reel efektif döviz kuru endeksi değişim oranının standart sapmasının hareketli ortalaması şeklinde hesaplanmış ve ekonomik analiz 1983:Q3-2000:Q4 dönemi verileri üzerinden yürütülmüştür. Çalışmada elde edilen bulgulara göre döviz kuru volatilitesi Türkiye ihracatını uzun ve kısa dönemde negatif etkilemektedir. Kasman ve Kasman (2005) ise döviz kuru volatilitesinin ihracata etkisini 1982:Q1-2001:Q4 Türkiye verileriyle incelemiştir. Çalışmanın kapsadığı dönem Saatçioğlu ve Karaca (2004)'ün analiz dönemi ile oldukça benzerlik göstermenin yanı sıra Kasman ve Kasman (2005)'te de Saatçioğlu ve Karaca (2004)'te kullanılan ekonometrik analiz yöntemi kullanılmıştır. Ayrıca her iki çalışmada da döviz kuru volatilitesinin hesaplanmasinda hareketli standart sapma yöntemi kullanılmıştır. Kasman ve Kasman (2005), döviz kuru volatilitesinin Türkiye ihracat1na etkisini reel döviz kuru, nominal efektif dolar/TL kuru ve nominal efektif Alman markı/TL kuru volatilitesini ihracat talep fonksiyonuna ayrı ayrı dahil ederek analiz etmekte olduğu için, bu üç modelden elde edilen sonuçların karşılaştırılabilmesi imkanını da vermektedir. İki çalışmanın birbirinden ayrıldığı diğer bir nokta ise modele volatilite değişkeni dışında dahil edilen açılkayıcı değişkenlerdir. Kasman ve 
Kasman (2005), ekonometrik analizi volatilite değişkeninin dahil edildiği klasik ihracat talep modeli üzerinden yürütmüştür. Saatçioğlu ve Karaca (2004) ise talep modeline döviz kuru volatilitesi ile birlikte reel döviz kurunu ve mevsim kuklasını dahil etmiştir. İnceleme dönemi, volatilite hesaplama yöntemi ve ekonometrik analiz metodu bakımından birbirine oldukça benzeyen iki çalışmanın sonuçları farklılık göstermektedir. Kasman ve Kasman (2005), Saatçioğlu ve Karaca (2004)'te ulaşılan sonuçların aksine, reel döviz kuru volatilitesinin Türkiye ihracatı üzerine kısa ve uzun dönemde anlamlı pozitif etkisi olduğu şeklinde bir sonuç elde etmiş̧ir. Nominal döviz kuru volatilitesinin ihracata etkisi ise kısa dönemde negatif iken; uzun dönemde yine pozitif bulunmuştur. $\mathrm{Bu}$ karşılaştırma döviz kuru volatilitesinin ihracata etkisi araştırılırken modele dahil edilen diğer bağımsız değişkenlerin sonucu önemli ölçüde değiştirebildiğini göstermesi açısından önemlidir.

Köse, Ay ve Topallı (2008), 1995:01-2008:06 dönemi için döviz kuru volatilitesinin Türkiye ihracatına etkisini araştırmış ve logaritmik birinci sıra farkı alınan reel döviz kurunun standart sapması, reel döviz kurudaki değişmenin hareketli standart sapması ve GARCH modeli kullanılarak hesaplanan koşullu varyans olmak üzere 3 farklı volatilite ölçüsü kullanmıştır. Johansen eşbütünleşme testi ve hata düzeltme modeli sonuçları, döviz kuru volatilitesinin Türkiye ihracatı üzerinde kısa ve uzun dönemde anlamlı ve olumsuz etkisinin bulunduğunu; ancak bu etkinin 2 ay gibi bir sürede ortadan kalktığını işaret etmiştir. Öztürk ve Kalyoncu (2009), döviz kuru volatilitesinin Güney Afrika, Güney Kore, Pakistan, Polonya, Macaristan ve Türkiye’nin ihracatı üzerine etkisini 1980:Q1-2005:Q4 verileri ile incelemiştir. Reel döviz kuru artış oranının 4 dönemlik hareketli standart sapmasının volatilite ölçüsü olarak kullanıldığı çalışmada analiz sonuçları, döviz kuru volatilitesinin kısa dönemde Güney Kore, Pakistan, Polonya ve Güney Afrika ihracatına anlamlı negatif etkisi olduğunu göstermektedir. Uzun dönemde ise Polonya, Pakistan, Güney Kore ve Güney Afrika ihracatı döviz kuru volatilitesinden olumsuz etkilenirken; Türkiye ve Macaristan ihracatı pozitif etkilenmektedir. Tarı ve Yıldırım (2009), ihracat talep modeline mevsimsel etkiyi de dahil ederek döviz kuru volatilitesinin Türkiye ihracatına etkisini 1989:Q12007:Q3 dönemi için incelemiştir. Johansen eşbütünleşme testi ve hata düzeltme modeli ile analiz edilen ihracat talep modelinde yer alan volatilite değişkeni, reel döviz kurunun standart sapmasının 8 dönemlik hareketli ortalaması şeklinde hesaplanmıştır. Çalışmada döviz kuru volatilitesinin kısa dönemde Türkiye ihracatı üzerinde anlamlı bir etkisinin olmadığı, uzun dönemde ise etkinin anlamlı ve negatif olduğu sonucu elde edilmiştir.

Reel döviz kuru volatilitesinin Türkiye’nin ikili ihracat hacmi üzerine etkisini araştıran Vergil (2002), 1990:01-2000:12 dönemini kapsamakta ve reel döviz kurunun tahmin edilen trendi etrafındaki varyansı ile reel döviz kuru yüzde değişimlerinin 12 aylık standart sapması olmak üzere iki farklı volatilite ölçüsü kullanmaktadır. Türkiye’nin ABD, Fransa, Almanya ve İtalyảya gerçekleştirdiği reel ihracata reel döviz kuru volatilitesinin etkisinin incelendiği çalışmada, volatilitenin hem kısa dönemde hem de uzun dönemde Almanyàya olan ihracata negatif etkisi olduğu sonucuna ulaşılmıştır. Ayrıca elde edilen bulgular, uzun dönemde $A B D$ ve Fransa ile olan ihracatın da döviz kuru volatilitesinden olumsuz etkilendiğini göstermiştir. Doğru ve Uysal (2013) ise döviz kuru volatilitesinin Türkiye’nin ikili ihracatı üzerine etkisini, Türkiye-Euro bölgesi ihracatını ele alarak incelemiştir. 2002:01-2010:12 aylık verileriyle yürütülen çalışmada reel efektif döviz kuru volatilitesi, 12 dönemlik hareketli standart sapma yöntemi ve GARCH modeli ile elde edilmiştir. Çalışmada elde edilen ARDL sınır testi sonuçları, döviz kuru volatilitesinin Türkiye-Euro bölgesi ihracatını kısa dönemde anlamlı ve negatif, uzun dönemde ise pozitif etkilediği şeklindedir. Ancak volatilite değişkeninin katsayıları her iki dönem için oldukça küçük elde edilmiştir.

Bu çalışmada, sektörel reel döviz kuru volatilitesinin Türkiye imalat sanayi ihracatı üzerindeki etkisi araştırılmıştır. Döviz kuru volatilitesinin dış ticaret hacmine etkilerini inceleyen geniş literatüre bir katkı olarak analizde, ISIC Rev 3. sinıflandırmasına göre her bir sektör için elde edilen sektörel reel döviz kuru üzerinden hesaplanan sektörel reel döviz kuru volatilitesi kullanılmış; böylece toplulaştırma sapmasının önüne geçilmeye çalışılmıştır. Çalışmanın izleyen kısımlarında veri seti ve model tanitıldıktan sonra, sektörel reel döviz kurunun ve sektörel reel döviz kuru üzerinden hesaplanan volatilite serilerinin elde edilişi anlatılmıştır. Ardından, yürütülen ekonometrik analizden elde edilen bulgular ortaya konularak bu bulgulara ilişkin değerlendirmeler sunulmaya çalışılmıştır. 


\section{Veri Seti ve Model}

Bu çalışmada, döviz kuru volatilitesinin ihracat üzerindeki etkisini incelemek amaciyla uzun dönem ihracat talep fonksiyonuna döviz kuru volatilitesi de- ğişkeni eklenmiştir. Döviz kuru volatilitesinin ihracata etkilerini araştırmakta kullanılacak model Eşitlik

(1)'de verildiği gibidir.

$$
\begin{array}{r}
\log \left(\mathrm{EX}_{\mathrm{it}}\right)=\beta_{0}+\beta_{1} \log \left(Y_{i t}^{*}\right)+\beta_{2} \log \left(R E E R_{i t}\right)+\beta_{3} \sigma_{i t}+\varepsilon_{i t}, \\
i=1, \ldots, 22, \quad t=1, \ldots, T
\end{array}
$$

Burada, $i$ sektörü için $t$ anındaki reel ihracat değeri $\mathrm{EX}_{\mathrm{it}}$; yurtdışı reel gelir $Y_{\mathrm{i}}^{*}$; sektörel reel döviz kuru $R E E R_{\mathrm{it}}$ ile ifade edilmektedir. $\sigma_{i t}$ ise $i$ sektörü için elde edilen reel döviz kuru kullanılarak hesaplanan $\mathrm{t}$ anındaki volatilite değeridir. Volatilite değişkeni d1şındaki değişkenler modelde logaritmik formda yer almaktadır. Modelde sabit terim $\beta_{0}$ ile gösterilmektedir. İhracatın gelir esnekliği $\beta_{1}$ 'in teorik olarak s1fırdan büyük olması beklenmektedir. İhracatın döviz kuru esnekliği $\beta_{2}$ için teorik beklenti negatif olması yönündedir. $\beta_{3}$ katsayısı ise negatif ya da pozitif değer alabilecektir.

Ekonometrik analizde kullanılan veri seti 2005:Q12012:Q2 dönemini kapsamaktadır. Reel ihracat değerleri, nominal ihracatın ihracat birim değer endeksine bölünmesiyle elde edilmiştir. Nominal ihracat ve ihracat birim değer endeksi veri seti Türkiye İstatistik Kurumu veri tabanından elde edilmiştir. İhracat birim değer endeksi için baz yılı 2003’tür. Yurtdışı gelir değişkeni için proxy olarak Türkiye’nin önemli dış ticaret ortağı olan 10 ülkenin GSYİH değerlerinin ağılıklandırılmış ortalaması kullanılmıştır. ${ }^{1}$ Yurtdışı gelir serisini elde etmekte kullanılan 10 ülke ve Türkiye için mevsimsel düzeltmesi yapılmış reel GSYİH verileri OECD.Stat veri tabanından elde edilmiştir.

1 Yurtdışı gelir değişkeni oluşturulurken ele alınan ülkeler Fransa, Hollanda, Almanya, İtalya, İngiltere, İspanya, Belçika, Rusya, ABD ve İsrail'dir. Her bir sektör için yurtdışı gelir değişkenini elde etmekte kullanılan ülke ağırlıkları, Türkiye’nin -ilgili sektörde ve 2009-2011 döneminde- ele alınan 10 ülkenin her birine olan ihracatının ele alınan 10 ülkeye olan toplam ihracatına bölünmesiyle elde edilmiştir.
22 imalat sanayi sektörü için sektörel reel döviz kuru ve sektörel reel döviz kuru volatilitesi serileri yazarlar tarafından elde edilmiştir. Serilerin elde edilmesi bir sonraki başlık altında anlatılacaktır.

\section{Sektörel Reel Döviz Kuru ve Sektörel Reel Döviz Kuru Volatilitesi Serilerinin Elde Edilmesi}

Döviz kuru volatilitesinin Türkiye imalat sanayi sektörü ihracatına etkisini araştırmak üzere kurulan modelde kullanılmak üzere, öncelikle ISIC Rev 3. sinıflandırmasına göre 22 imalat sanayi sektörü için sektörel reel döviz kurları elde edilmiştir. Sektörel reel döviz kurları hesaplanırken 2003:Q1-2012:Q2 dönemi üç aylık verileri kullanılmıştır. Ülke kapsamı olarak, Türkiye’nin sektörel dış ticaretinde 2009-2011 dönemi ortalamasında en yüksek ağırlığa sahip 68 ülke ele alınmıştır. Yine sektörlerdeki son dönem gelişmelerin etkisini sektörel reel döviz kurlarına yansıtabilmek amacıyla, sektörel reel döviz kuru ağıllıklarının hesaplanmasında 2009-2011 dönemi ortalama ikili ticaret akımları kullanılmıştır. Sektörel reel döviz kuru hesaplama yöntemi olarak Lee ve Yi (2005)'te kullanılan geometrik hesaplama yöntemi benimsenmekle birlikte; dış ticaret hacmi ağırlığına sektörel ithalat ve ihracatın sektörel dış ticaret hacmi içerisindeki paylarını da yansıtmak üzere, ikili genel ağırlıklar Saygılı vd. (2012)'de uygulanan yöntem izlenerek hesaplanmıştır. İthalat, ihracat ve dış ticaret ağırlıklarının hesaplandığı formüller sırasıyla aşağıda verilmiştir.

Her bir sektörü için dış ticaret ağırlıklı döviz kuru, Eşitlik (2)'de verilmiştir. 


$$
\begin{aligned}
& R E E R_{S}=\prod_{j=1}^{N}\left(\mathrm{rer}_{j}\right)^{w t_{j}^{i}} \\
& w t_{j}^{i}=\left(\frac{\sum_{j=1}^{N} X_{j}^{i}}{\sum_{j=1}^{N} X_{j}^{i}+\sum_{j=1}^{N} M_{j}^{i}}\right) w x_{j}^{i}+\left(\frac{\sum_{j=1}^{n} M_{j}^{i}}{\sum_{j=1}^{N} X_{j}^{i}+\sum_{j=1}^{N} M_{j}^{i}}\right) w m_{j}^{i}, \\
& w x_{j}^{i}=\frac{X_{j}^{i}}{\sum_{j=1}^{N} X_{j}^{i}}, w m_{j}^{i}=\frac{M_{j}^{i}}{\sum_{j=1}^{N} M_{j}^{i}}
\end{aligned}
$$

Burada $w x_{j}^{\mathrm{i}}, w m_{\mathrm{j}}^{\mathrm{i}}$ ve $w t_{\mathrm{j}}^{\mathrm{i}}$ sirasıyla Türkiye’nin $i$ sektörü ihracatı, ithalatı ve dış ticaret hacmi içindeki $j$ ülkesi ihracat, ithalat ve dış ticaret hacminin ağırlıklarıdır. $X_{j}^{\mathrm{i}}, i$ ülkesine yapılan toplam ihracat; $M_{j}^{\mathrm{i}}$, $i$ ülkesinden yapılan toplam ithalat; $N$ ise hesaplamaya dahil edilen ülke sayısıdır. rer, $j$ j ülkesi para birimi ile Türk Lirasının birbiriyle değişim oranının fiyat etkisinden arındırılmış halini, yani reel döviz kurunu temsil etmektedir. Reel döviz kuru Eşitlik (3)’te gösterildiği gibidir.

$$
\operatorname{rer}_{j}=\frac{P_{i}}{P_{i}^{j} \times e_{i, t r}}
$$

$e_{i, t r}$, bir birim $j$ ülkesi parası karşıllı̆̆ında verilen TL miktarı şeklinde ifade edilen ikili döviz kurunu; $P_{i}$ ve $P_{i}^{j}$ ise sırasıyla Türkiye ve $j$ diş ticaret ortağının fiyat endekslerini simgelemektedir. Hesaplanan sektörel reel döviz kurundaki bir artış TL'nin değer kazandığını, dolayısıyla da $i$ sektörü altında sınıflandırılmış malların fiyatının yabancı mallara göre daha pahalı hale geldiğini göstermektedir.

İmalat sanayi sektörleri için sektörel reel döviz kuru verilerinin elde edilmesinin ardından, sektörel reel döviz kurları kullanılarak volatilite hesaplamaya geçilmeden önce, sektörel reel döviz kurlarının ARCH yapıları araştırılmıştır. Bu amaçla 22 sektör için hesaplanan sektörel reel döviz kuru serilerinin durağan olup olmadıkları incelenmiştir. ADF birim kök testi sonuçları her bir sektörel reel döviz kuru serisinin düzeyde durağan olduğunu göstermiştir. Ardından volatilite hesaplama yöntemi olarak ARCH temelli bir model kullanılıp kullanılamayacağını araştırmak üzere, her bir sektörel reel kur serisi için en uygun ARMA modeli bulunmaya çalışılmıştır. Daha sonra, her bir seri için elde edilen uygun ARMA modelinin hata terimlerinde ARCH etkisi olup olmadığını görmek amacıyla ARCH-LM testi uygulanmıştır. 1., 4., 8. ve 12. gecikmelerle tekrarlanan ARCH-LM testi sonuçları, her bir sektörel reel döviz kuru serisi için en uygun ARMA modelinden elde edilen hata terimlerinde ARCH etkisi olmadığını göstermiştir. Dolayısıyla, volatilite hesaplama yöntemi olarak ARCH temelli modellerden herhangi birinin kullanılmasının doğru bir yaklaşım olmadığına karar verilmiştir.

Çalışmada volatilite hesaplama yöntemi olarak, döviz kuru volatilitesinin dış ticaret hacmi üzerindeki etkilerini araştıran literatürde kullanılan üç farklı yöntem benimsenmiş, ayrıca döviz kuru volatilitesinin daha küçük hesaplanmasına olanak veren bir yöntem daha kullanılmıştır. Volatilite hesaplamasında dört farklı yöntem ele alınmasıyla, döviz kuru volatilitesinin dış ticaret hacmi üzerindeki etkisi araştırılırken, volatilite hesaplama yöntemi farklılıklarının farklı sonuçlar elde edilmesine neden olup olmadığını inceleme imkanı da araştırma sürecine dahil edilmiştir. Çalışmada kullanılan volatilite hesaplama yöntemleri aşağıdaki gibidir.

- $\sigma_{1}$, logaritmik düzeydeki sektörel reel döviz kurlarının bir önceki döneme göre değişimlerinin 8 dönemlik hareketli ortalama yöntemiyle elde edilen standart sapmasi,

- $\sigma_{2}$, logaritmik düzeydeki sektörel reel döviz kurlarının uygun trend modelinden sapmalarının 8 dönemlik hareketli ortalama yöntemiyle elde edilmiş standart sapması,

- $\sigma_{3}$, logaritmik düzeydeki sektörel reel döviz kurlarının AR(1) modelinden sapmalarının 8 dönemlik hareketli ortalama yöntemiyle elde edilmiş standart sapması, 
- $\sigma_{4}$, logaritmik düzeydeki sektörel reel döviz kurlarının uygun ARMA modelinden sapmalarının 8 dönemlik hareketli ortalama yöntemiyle elde edilmiş standart sapması şeklinde hesaplanmıştır. Bu yöntem, AR modelinden sapmaların kullanıldığ döviz kuru volatilitesi hesaplama yönteminin özelleştirilmiş halidir. Bu hesaplama yöntemi, döviz kuru volatilitesinin diğer yöntemlerle elde edilen değerlere göre daha küçük değerler almasına imkân vermektedir. Bu ise, ekonomik analiz sonunda döviz kuru volatilitesi katsayısinın volatilite hesaplama yöntemiyle bağlantılı olarak ciddi farklılıklar gösterip göstermediğinin incelenmesi açısından önemlidir.

\section{Ekonometrik Analiz}

Sektörel reel döviz kuru volatilitesinin ihracat hacmi üzerindeki etkilerini Eşitlik (1)'de verilen model ile analiz etmeye geçmeden önce, modelde yer alan değişkenlerin durağan olup olmadığı araştırılmıştır. Çalışmada panel veri setini oluşturan değişkenlerin durağan olup olmadığı Levin, Lin ve Chu (2002) panel birim kök testi süreci ile sınanmıştır. Levin, Lin ve Chu (LLC) panel birim kök testi, sabit ve trend içermeyen, yalnız sabit içeren ve sabit ve trendi birlikte içeren üç farklı model kullanarak uygulanabilmektedir. LLC testi için sıfır hipotezi ve alternatif hipotez aşağıda belirtildiği gibidir.

$\mathrm{H}_{0}$ : Panel verideki her bir yatay kesit birimine ait zaman serisi birim kök içermektedir.

$\mathrm{H}_{1}$ : Panel verideki her bir yatay kesit birimine ait zaman serisi birim kök içermemektedir.

LLC testi uygulanırken her bir değişken için gecikme uzunlukları Schwarz enformasyon kriterine göre belirlenmiştir. Modelde yer alan değişkenlere uygulanan LLC testi sonuçları Tablo 1' de verilmiştir.

Tablo 1. LLC Panel Birim Kök Test Sonuçları

\begin{tabular}{|c|c|c|c|c|c|c|}
\hline \multirow[b]{2}{*}{ Değişken } & \multicolumn{2}{|c|}{$\begin{array}{c}\text { Model (1) } \\
\text { (Sabit ve Trend } \\
\text { içermeyen) }\end{array}$} & \multicolumn{2}{|c|}{$\begin{array}{c}\text { Model (2) } \\
\text { (Sabit terim içeren) }\end{array}$} & \multicolumn{2}{|c|}{$\begin{array}{c}\text { Model (3) } \\
\text { (Sabit terim ve trend } \\
\text { içeren) }\end{array}$} \\
\hline & t-İstatistiği & Olasılik(t) & t-İstatistiği & Olasılik(t) & t-İstatistiği & Olasılik (t) \\
\hline $\log (E X)$ & 6.77539 & 1.0000 & -2.64305 & 0.0041 & -3.96579 & 0.0000 \\
\hline $\log \left(Y^{*}\right)$ & 5.41506 & 1.0000 & -6.26811 & 0.0000 & -5.25133 & 0.0000 \\
\hline $\log \left(R E E R_{s}\right)$ & 2.88171 & 0.9980 & -7.95660 & 0.0000 & -3.48320 & 0.0002 \\
\hline$\sigma_{1}^{S}$ & -3.20947 & 0.0007 & -5.12945 & 0.0000 & -3.63042 & 0.0001 \\
\hline$\sigma_{2}^{S}$ & -0.85129 & 0.1973 & -3.23726 & 0.0006 & 1.73484 & 0.9586 \\
\hline$\sigma_{3}^{S}$ & -1.48986 & 0.0681 & -2.85015 & 0.0022 & -2.30954 & 0.0105 \\
\hline$\sigma_{4}^{S}$ & -0.95118 & 0.1708 & -1.34230 & 0.0897 & 0.47252 & 0.6817 \\
\hline
\end{tabular}

Tablo 1'de verilen sonuçlara göre $\log (\mathrm{EX}), \log \left(Y^{*}\right)$ ve $\log \left(R E E R^{s}\right)$ değişkenleri, sadece sabitin dahil edildiği ve trend ve sabitin birlikte dahil edildiği model göz önünde bulundurulduğunda birim kök içermemektedir. Volatilite değişkenleri için elde edilen test sonuçlarına göre ise sadece sabitin dahil edildiği model- de reel döviz kuru volatilitesi değişkenleri birim kök içermemektedir. $\sigma_{4}^{S}$ için $\% 10$ anlam düzeyinde birim kök içermediği sonucuna varılabilirken, diğer volatilite değişkenleri için sıfır hipotezi \%1 anlam düzeyinde reddedilmektedir. Ancak, sabit terim ve trendin birlikte dahil edildiği modelde yalnızca $\sigma_{1}^{S}$ ve $\sigma_{4}^{S}$ 
değişkenleri durağan olarak karşımıza çıkmaktadir. Model (2) ve Model (3)'ten elde edilen bulgular farklılaştı̆̆ 1 için volatilite değişkenlerinin grafikleri incelenmiş ve trende sahip olmadıkları görülmüştür. Dolayısıyla Model (2)'deki sonuçlara dayanarak volatilite değişkenlerinin birim kök içermediği söylenebilmektedir.

İhracat talep modelinde yer alacak değişkenlerin birim köke sahip olmadıkları belirlendikten sonra, sektörel reel döviz kuru volatilitesinin ihracat hacmi üzerindeki etkilerini araştırmak için Eşitlik (1), panel veri analizi ile hem sabit etkiler hem de rassal etkiler modeli kullanılarak tahmin edilmiştir. Tahminleme yapılırken, sonuçların volatilite hesaplama yönteminden kaynaklanan farklılıklar içerip içermediğini inceleyebilmek amacıyla, hesaplanan dört farklı volatilite değişkeniyle dört farklı model kurulmuştur. Sabit etkiler modeli kullanılarak uygulanan panel veri analizi sonuçları Tablo 2' de verilmiştir.

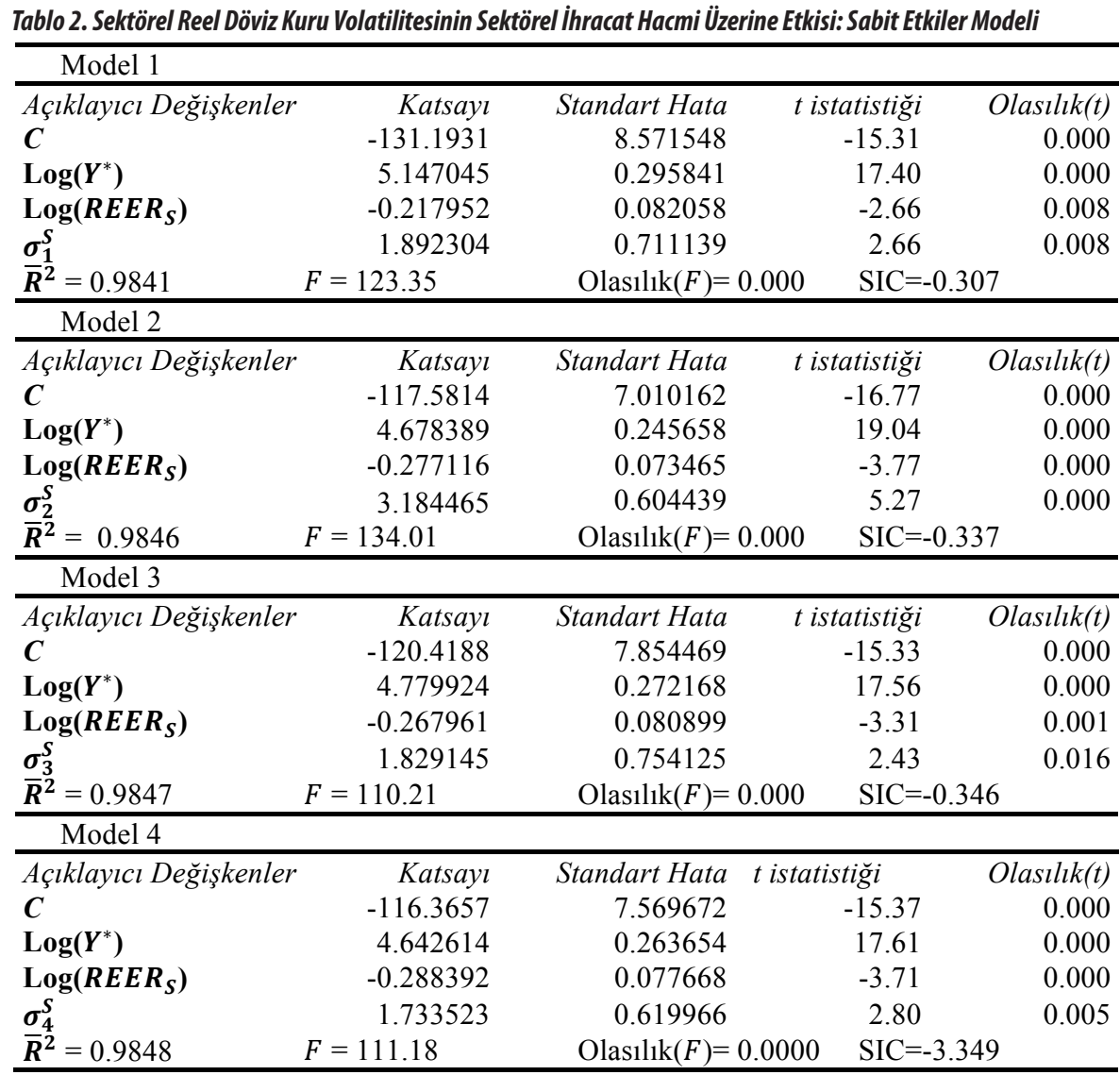

Tablo 2' de verilen dört modelin sonuçları da sektörel reel ihracat hacminin reel diş gelirdeki bir artıştan olumlu etkilenerek artış yönünde hareket gösterdiğini işaret etmektedir. Elde edilen ihracatın gelir esnekliği değerleri yaklaşık olarak \%5 seviyesinde olup, dış gelirdeki \%1 düzeyindeki bir artışın imalat sanayi sektörleri ihracatı üzerinde yaklaşık $\% 5$ oranında artış yarattığı şeklinde yorumlanabilir. İhracatın döviz kuru esnekliği değeri ise modellerin tümü için nega- tif değer almaktadır. Elde edilen döviz kuru esnekliği değerlerine göre döviz kurundaki \%1'lik bir artış, imalat sanayi sektörleri ihracatını \% $0.2-0.3$ oranında azaltmaktadır.

Döviz kuru volatilitesi değişkenleri ise modellerde pozitif katsayı almaktadır. Bu durum, döviz kuru volatilitesindeki artışların ihracat üzerindeki etkisinin artış yönünde olduğu anlamına gelmektedir. Modellerin 
her birinden elde edilen ihracatın gelir ve döviz kuru esnekliği katsayıları oldukça yakın değerler alırken; reel döviz kurunun uygun trendden sapmaları kullanılarak hesaplanan volatilite değişkeninin yer aldığı ikinci modelde, döviz kuru volatilitesine ait katsayı diğer modellerden elde edilen katsayılardan oldukça yüksek elde edilmiştir. Diğer üç modelden elde edilen volatilite katsayıları ise birbirine yakın görünmektedir. Sabit etkiler modeli kullanılarak en küçük kareler yöntemi ile elde edilen her dört modeldeki katsayılar bireysel olarak ve modeller bir bütün olarak anlamlı görünmektedir. Dört modelden elde edilen sonuçlar, döviz kuru volatilitesinin reel ihracat üzerinde pozitif ve anlamlı bir etkisi olduğunu göstermektedir.

Farklı volatilite ölçülerinin yer aldığ 14 modelden hangisinin daha uygun bir sektörel ihracat talep modeli olduğunu belirlemek için Schwarz bilgi kriterine başvurulmuştur. Schwarz bilgi kriterinin daha küçük elde edildiği ve uygun ARMA modelinden sapmaların hareketli standart sapması şeklinde hesaplanan volatilite değişkeninin yer aldığı Model (4), diğer modellere göre daha uygun bir model olarak görünmektedir. Ancak AR(1) modelinden sapmaların hareketli standart sapması şeklinde hesaplanan volatilite değiş- keninin yer aldığı Model (3) de Model (4)'e oldukça yakın bir Schwarz bilgi kriteri değerine sahiptir.

Tablo 3' te ise yine dört farklı yöntemle elde edilmiş döviz kuru volatilitesi değişkenini içeren modeller için, rassal etkiler modeli kullanılarak uygulanabilir en küçük kareler yöntemiyle elde edilen analiz sonuçları verilmiştir. Rassal etkiler modeli sonuçlarına göre, tahmin edilen dört modeldeki değişkenlere ait katsayılar, sabit etkiler modelinden elde edilen katsayılarda olduğu gibi, bireysel olarak ve modeller de bir bütün olarak anlamlıdır. Tahmin edilen her model için elde edilen sonuçlar sabit etkiler modeli sonuçlarıyla karşılaştırıldığında; katsayıların işaretleri ve aldıkları değerlerin birbirinden çok farklı olmadığ görülmektedir. Rassal etkiler modeli kullanılarak yapılan analiz ile elde edilen ihracatın gelir esneklikleri katsayıları, sabit etkiler modelinden elde edilen katsayılara göre nispeten daha küçük elde edilmiştir. Her bir model için elde edilen ihracat gelir ve talep esnekliklerinin aldığı işaretler teorik beklentiye uygundur. Rassal etkiler modeli kullanılarak elde edilen sonuçlara göre de döviz kuru volatilitesinin ihracat üzerindeki etkisi pozitiftir.

\begin{tabular}{|c|c|c|c|c|}
\hline \multicolumn{5}{|l|}{ Model 1} \\
\hline Açıklayıcı Değişkenler & Katsayı & Standart Hata & $z$ istatistiği & Olasılık(t) \\
\hline C & -119.763 & 8.409262 & -14.24 & 0.000 \\
\hline $\log \left(Y^{*}\right)$ & 4.752305 & 0.289978 & 16.39 & 0.000 \\
\hline $\log \left(R E E R_{S}\right)$ & -0.234502 & 0.083341 & -2.81 & 0.005 \\
\hline$\sigma_{1}^{S}$ & 1.386506 & 0.715649 & 1.94 & 0.053 \\
\hline $\boldsymbol{R}^{2}=0.3599$ & \multicolumn{2}{|c|}{ Wald $\chi^{2}=333.85$} & \multicolumn{2}{|c|}{ Olasılik $\left(\chi^{2}\right)=0.0000$} \\
\hline \multicolumn{5}{|l|}{ Model 2} \\
\hline Açıklayıcı Değişkenler & Katsayı & Standart Hata & $z$ istatistiği & Olasılık(z) \\
\hline C & -110.1501 & 6.935288 & -15.88 & 0.000 \\
\hline $\log \left(Y^{*}\right)$ & 4.41785 & 0.242731 & 18.20 & 0.000 \\
\hline $\log \left(R E E R_{S}\right)$ & -0.269221 & 0.074511 & -3.61 & 0.000 \\
\hline$\sigma_{2}^{S}$ & 3.213867 & 0.613063 & 5.24 & 0.000 \\
\hline $\boldsymbol{R}^{\mathbf{2}}=0.3795$ & \multicolumn{2}{|c|}{ Wald $\chi^{2}=369.32$} & \multicolumn{2}{|c|}{ Olasil1k $\left(\chi^{2}\right)=0.0000$} \\
\hline \multicolumn{5}{|l|}{ Model 3} \\
\hline Açıklayıcı Değişkenler & Katsayı & Standart Hata & $z$ istatistiği & Olasilık(z) \\
\hline C & -111.3362 & 7.732894 & -14.40 & 0.000 \\
\hline $\log \left(Y^{*}\right)$ & 4.464977 & 0.267673 & 16.68 & 0.000 \\
\hline $\log \left(R E E R_{S}\right)$ & -0.276437 & 0.082057 & -3.37 & 0.001 \\
\hline$\sigma_{3}^{S}$ & 1.624502 & 0.763786 & 2.13 & 0.033 \\
\hline $\boldsymbol{R}^{2}=0.3423$ & \multicolumn{2}{|c|}{ Wald $\chi^{2}=299.82$} & \multicolumn{2}{|c|}{ Olasilik $\left(\chi^{2}\right)=0.0000$} \\
\hline \multicolumn{5}{|l|}{ Model 4} \\
\hline Açıklayıcı Değişkenler & Katsayl & Standart Hata & $z$ istatistiği & Olasılık(z) \\
\hline C & -107.9467 & 7.459457 & -14.47 & 0.000 \\
\hline $\log \left(Y^{*}\right)$ & 4.349288 & 0.259532 & 16.76 & 0.000 \\
\hline $\log \left(R E E R_{S}\right)$ & -0.289953 & 0.078768 & -3.68 & 0.000 \\
\hline & 1.708398 & 0.628698 & 2.72 & 0.007 \\
\hline $\boldsymbol{R}^{2}=0.3443$ & \multicolumn{2}{|c|}{ Wald $\chi^{2}=303.62$} & \multicolumn{2}{|c|}{ Olasil1k $\left(\chi^{2}\right)=0.0000$} \\
\hline
\end{tabular}


Rassal ve sabit etkiler modellerinden elde edilen sonuçlar büyük farklılıklar göstermemekle birlikte; hangi yöntemin daha uygun olduğunu test etmek amaciyla Hausman (1978) testi uygulanmıştır. Hausman testi sonuçları Tablo 4' te verilmektedir. Hausman testinde $\mathrm{H}_{0}$ hipotezinde bireysel etkilerle açıklayıcı değişkenler arasında ilişki yoktur hipotezi yer alırken; $\mathrm{H}_{1}$ hipotezi bireysel etkilerle açıklayıcı değişkenler arasında ilişki olduğu şeklindedir. Test sürecinde sabit etkiler ve ras- sal etkiler modelleri kullanılarak elde edilen katsayılar arasındaki farklar göz önünde bulundurulmaktadır. Farklı reel döviz kuru volatilitesi değişkenlerinin yer aldığ1 dört model için uygulanan Hausman testi sonuçlarına göre, \%1 anlam düzeyinde açıklayıcı değişkenler ile bireysel etkiler arasında ilişki bulunmadığ́nı ileri süren $\mathrm{H}_{0}$ hipotezi reddedilmektedir. Dolayısıyla dört ihracat modelinden her biri için sabit etkiler modeli daha uygun bir model olarak belirlenmiştir.

Tablo 4. İhracat Talep Modelleri için Hausman Testi Sonuçları

\begin{tabular}{lcrrrrrrr}
\hline Açıklayıcı & \multicolumn{2}{c}{ Model 1 } & \multicolumn{2}{c}{ Model 2 } & \multicolumn{2}{c}{ Model 3 } & \multicolumn{2}{c}{ Model4 } \\
Değişkenler & Fixed & Random & Fixed & Randon & Fixed & Random & Fixed & Random \\
\hline $\mathbf{L o g}\left(\boldsymbol{Y}^{*}\right)$ & 5.147 & 4.752 & 4.678 & 4.417 & 4.779 & 4.465 & 4.643 & 4.349 \\
$\mathbf{L o g}\left(\boldsymbol{R E E} \boldsymbol{R}_{\boldsymbol{S}}\right)$ & -0.218 & -0.235 & -0.277 & -0.269 & -0.267 & -0.276 & -0.288 & -0.289 \\
$\boldsymbol{\sigma}^{\boldsymbol{S}}$ & 1.892 & 1.387 & 3.184 & 3.214 & 1.829 & 1.625 & 1.734 & 1.708 \\
\hline \multirow{2}{*}{ Hausman } & $\chi^{2}=45.35$ & $\chi^{2}=47.35$ & $\chi^{2}=40.84$ & $\chi^{2}=39.87$ \\
& $\mathrm{p}=0.0000$ & $\mathrm{p}=0.0000$ & $\mathrm{p}=0.0000$ & $\mathrm{p}=0.0000$ \\
\hline
\end{tabular}

Sektörel reel döviz kuru volatilitesinin ihracat üzerine etkilerini araştırmak amacıyla uygulanan panel veri analizinde sabit etkiler modelinin kullanılmasının daha uygun olacağ ${ }_{1}$ belirlendikten sonra, sabit etkiler modeliyle tahmin edilen dört ihracat talep modelinden elde edilen hata terimlerinin otokorelasyon ve değişen varyansa sahip olup olmadıkları test edilmiştir. Bu amaçla, hata terimlerinin değișen varyans özelliği gösterip göstermediğini sınamak için modifiye edilmiş Wald testi ve birinci dereceden otokorelasyon içerip içermediğini test etmek için Wooldridge testi kullanılmıştır.

Tablo 5. İhracat Talep Modelleri için Modifiye Edilmiş Wald ve Wooldridge Testi Sonuçları

\begin{tabular}{|c|c|c|c|c|c|c|c|c|}
\hline \multirow[b]{2}{*}{$\begin{array}{l}\text { Tanımlayıct } \\
\text { Test }\end{array}$} & \multicolumn{2}{|c|}{ Model 1} & \multicolumn{2}{|c|}{ Model 2} & \multicolumn{2}{|c|}{ Model 3} & \multicolumn{2}{|c|}{ Model4 } \\
\hline & $\begin{array}{c}\text { Test } \\
\text { Istatistiği }\end{array}$ & Olasılık & $\begin{array}{c}\text { Test } \\
\text { İstatistiŏgi }\end{array}$ & Olasılık & $\begin{array}{c}\text { Test } \\
\text { Istatistiği }\end{array}$ & Olasilık & $\begin{array}{c}\text { Test } \\
\text { İstatistiği }\end{array}$ & Olasılık \\
\hline $\begin{array}{l}\text { Modifiye } \\
\text { edilmiş } \\
\text { Wald Testi }\end{array}$ & $\chi^{2}=711.2$ & 0.0000 & $\chi^{2}=1087.7$ & 0.0000 & $\chi^{2}=650.3$ & 0.0000 & $\chi^{2}=642.1$ & 0.0000 \\
\hline $\begin{array}{l}\text { Wooldridge } \\
\text { Testi }\end{array}$ & $F=27.39$ & 0.0000 & $\mathrm{~F}=27.71$ & 0.0000 & $\mathrm{~F}=24.20$ & 0.0001 & $\mathrm{~F}=23.83$ & 0.0001 \\
\hline
\end{tabular}

Sabit etkiler modeli kullanılarak tahmin edilen ihracat talep modellerinin modifiye edilmiş Wald ve Wooldridge testi sonuçları Tablo 5' te verilmiştir. Bu sonuçlara göre farklı şekilde hesaplanmış sektörel reel döviz kuru volatilitesi değişsenlerinin yer aldığı modellerin her birinden elde edilen hata terimleri hem otokorelasyon hem de değişen varyanslılık özelliği sergilemektedir. Bu yüzden sabit etkiler modeli kul- lanılarak hesaplanan standart hatalara değişen varyans ve otokorelasyon düzeltmesi yapılması gerekmektedir. Tablo 6' da sabit etkiler modeli ile yapılan katsayı tahminleri, otokorelasyon ve değişen varyans düzeltmesi yapılmış (robust) standart hataları ve bu standart hatalar üzerinden hesaplanan istatistikleri ile birlikte sunulmuştur. 
Tablo 6. Sektörel Reel Döviz Kuru Volatilitesinin Sektörel Ihracat Hacmi Üzerine Etkisi: Sabit Etkiler Modeli (Düzeltilmiş Standart Hatalar)

\begin{tabular}{|c|c|c|c|c|}
\hline Model 1 & & & & \\
\hline Açıklayıcı Değişkenler & Katsayl & $\begin{array}{r}\text { Standart Hata } \\
\text { (robust) }\end{array}$ & $t$ istatistiğ $i$ & Olasılık(t) \\
\hline$C$ & -131.1931 & 20.43738 & -6.42 & 0.000 \\
\hline $\log \left(Y^{*}\right)$ & 5.147045 & 0.711684 & 7.23 & 0.000 \\
\hline $\log \left(R E E R_{S}\right)$ & -0.217952 & 0.093793 & -2.32 & 0.030 \\
\hline$\sigma_{1}^{S}$ & 1.892304 & 0.891056 & 2.12 & 0.046 \\
\hline$\overline{\boldsymbol{R}}^{\mathbf{2}}=0.9841$ & $F=24.69$ & \multicolumn{3}{|c|}{ Olasilik $(F)=0.0000$} \\
\hline \multicolumn{5}{|l|}{ Model 2} \\
\hline Açıklayıcı Değişkenler & Katsayl & $\begin{array}{r}\text { Standart Hata } \\
\text { (robust) }\end{array}$ & $t$ istatistiği & Olasılık(t) \\
\hline$C$ & -117.5814 & 16.46833 & -7.14 & 0.000 \\
\hline $\log \left(Y^{*}\right)$ & 4.678389 & 0.576158 & 8.12 & 0.000 \\
\hline $\log \left(R E E R_{S}\right)$ & -0.277116 & 0.078201 & -3.54 & 0.002 \\
\hline$\sigma_{2}^{S}$ & 3.184465 & 1.486001 & 2.14 & 0.044 \\
\hline$\overline{\boldsymbol{R}}^{2}=0.9846$ & $F=31.94$ & \multicolumn{3}{|c|}{ Olasıl1 $\mathrm{k}(F)=0.0000$} \\
\hline \multicolumn{5}{|l|}{ Model 3} \\
\hline Açıklayıcı Değişkenler & Katsayı & $\begin{array}{r}\text { Standart Hata } \\
\text { (robust) }\end{array}$ & $t$ istatistiğ $i$ & Olastlık(t) \\
\hline$C$ & -120.4188 & 16.90501 & -7.12 & 0.000 \\
\hline $\log \left(Y^{*}\right)$ & 4.779924 & 0.593885 & 8.05 & 0.000 \\
\hline $\log \left(R E E R_{S}\right)$ & -0.267961 & 0.093372 & -2.87 & 0.009 \\
\hline$\sigma_{3}^{S}$ & 1.829145 & 1.07733 & 1.70 & 0.104 \\
\hline$\overline{\boldsymbol{R}}^{\mathbf{2}}=0.9847$ & $F=27.95$ & \multicolumn{3}{|c|}{ Olasılık $(F)=0.0000$} \\
\hline \multicolumn{5}{|l|}{ Model 4} \\
\hline Açıklayıcı Değişkenler & Katsayı & $\begin{array}{r}\text { Standart Hata } \\
\text { (robust) }\end{array}$ & $t$ istatistiğ $i$ & Olasılık(t) \\
\hline$C$ & -116.3657 & 15.80999 & -7.36 & 0.000 \\
\hline $\log \left(Y^{*}\right)$ & 4.642614 & 0.55828 & 8.32 & 0.000 \\
\hline $\log \left(R E E R_{S}\right)$ & -0.288392 & 0.095563 & -3.02 & 0.007 \\
\hline$\sigma_{4}^{S}$ & 1.733523 & 0.963496 & 1.80 & 0.086 \\
\hline$\overline{\boldsymbol{R}}^{\mathbf{2}}=0.9848$ & $F=25.49$ & \multicolumn{3}{|c|}{$\operatorname{Olas} 11 \mathrm{k}(F)=0.0000$} \\
\hline
\end{tabular}

Tablo 6' daki tahmin sonuçları incelendiğinde, tahmin edilen dört modelin her biri için elde edilen ihracatın gelir esnekliği ve Model (1)'den elde edilen ihracatın döviz kuru esnekliği katsayısı dışındaki döviz kuru esnekliği katsayıları, standart hata düzeltmesi yapılmamış tahmin sonuçlarında olduğu gibi, \%1 anlam düzeyinde bireysel olarak anlamlıdır. Model (1)'den elde edilen ihracatın döviz kuru esnekliği katsayısı ise $\% 5$ anlam düzeyinde bireysel anlamlılığını korumaya devam etmektedir.

Sektörel reel döviz kuru volatilitesi için elde edilen katsayılar ise Model (1) ve Model (2) için \%5 anlam düzeyinde anlamlılığını korumaya devam ederken, Model (4)'ten elde edilen volatilite katsayısı \%10 anlam düzeyinde bireysel olarak anlamlıdır. Model (3) kullanılarak tahmin edilen volatilite katsayısı ise standart sapmalara düzeltme uygulanmasının ardından bireysel anlamlılığını yitirmektedir. Ancak bu katsayı için elde edilen istatistiği \%10 anlam düzeyine çok yakın bir değer almaktadır. Model (1), Model (2) ve Schwarz bilgi kriterinden en uygun model olduğu bilgisi elde edilen Model (4) ile tahmin edilen volatilite katsayıları bireysel anlamlılı̆̆ını koruduğu için, sektörel reel döviz kurunun sektörel reel ihracat hacmi üzerinde pozitif etkisi olduğu sonucu geçerliliğini korumaktadır.

\section{Sonuç ve Değerlendirme}

Döviz kuru belirsizliği ile dış ticaret arasındaki ilişki, sabit döviz kuru rejiminden dalgalı döviz kuru rejimine geçişin başlangıcı olarak kabul edilen Bretton Woods sisteminin yıkılmasının ardından çok sayı- 
da teorik ve ampirik çalışmaya konu olmuştur. Döviz kuru volatilitesinin diş ticaret üzerinde olumsuz etkileri olduğuna dair görüş yaygın olsa da, döviz kurundaki öngörülemeyen değişmelerin dış ticaret hacmi üzerinde herhangi bir etkisinin olmadığı ya da bir etkisi olmakla birlikte, yaygın görüşün aksine, bu etkinin pozitif yönlü olduğuna yönelik teorik görüşler ve bu görüşleri destekleyen ampirik çalışmalar da oldukça fazladır.

Bu çalışmada, reel döviz kuru volatilitesinin Türkiye reel ihracatı üzerine etkisi 2005:Q1-2012:Q2 dönemi için ve ISIC Rev. 3'e göre sınıflandırılmış 22 imalat sanayi sektörü özelinde incelenmeye çalışılmıştır. Bu amaçla öncelikle 22 imalat sanayi sektörü için sektörel reel döviz kurları hesaplanmıştır. Böylece, ekonometrik analizde toplulaştırılmış reel döviz kurunun kullanılmasının yaratabileceği toplulaştırma sapmasının etkisi giderilmeye çalışılmıştır. Ardından hesaplanan sektörel reel döviz kurları üzerinden volatilite hesaplamasına geçilmiştir. Sektörel reel döviz kuru serilerinin ARCH yapılarını araştırmak amacıyla, her bir sektörel reel döviz kuru serisi için uygun ARMA modeli belirlenmiş ve bu modellerden elde edilen hata terimlerinin ARCH etkisi içerip içermediği incelenmiştir. Hata terimlerinin ARCH etkisi taşımaması nedeniyle, döviz kuru volatilitesinin hesaplanmasinda ARCH temelli bir modelin kullanılması uygun olmayacağ için çalışmada, hareketli standart sapma yöntemi ile hesaplanan dört farklı volatilite değişkeni kullanılmış ve böylece volatilite hesaplama yönteminin ekonometrik analiz sonuçları üzerinde farklılık yaratıp yaratmadığı araştırılmaya çalışılmıştır.

Sektörel reel döviz kuru volatilitesinin sektörel reel ihracat hacmi üzerine etkisini araştırmak için yürütülen panel veri analizi sonuçları, sektörel reel döviz kuru volatilitesinin sektörel reel ihracat üzerinde anlamlı ve pozitif etkisi olduğu şeklinde elde edilmiştir. Sektörel reel döviz kuru volatilitesinin sektörel reel ihracatı olumlu etkilediği yönünde ulaşllan bulgular, reel döviz kuru volatilitesinin Türkiye toplam ihracat hacmine etkisini inceleyen Kasman ve Kasman (2005) ile Öztürk ve Kalyoncu (2009) ve Türkiye-EU bölgesi reel ihracatı üzerine etkisini inceleyen Doğru ve Uysal (2013)'te elde edilen sonuçları desteklemektedir. Ekonometrik analiz ile elde edilen sonuç, sektörel reel döviz kuru volatilitesindeki artışın etkisinin, ithalat üzerinde ithalatı arttırıcı bir etkisi olmaması durumunda, dış ticaret açığını kapatıcı olduğu şeklinde yorumlanabilir.

\section{Kaynakça}

Bacchetta, P. ve Wincoop, E. V. (2000). Does exchangerate stability increase trade and welfare?. The American Economic Review, 90(5), 1093-1109.

Broll, U. ve Eckwert, B. (1999). Exchange rate volatility and international trade. Southern Economic Journal, 66(1), 178-185.

Canzoneri, M. B.; Clark, P. B.; Glaessner, T. C. ve Leahy, M. P. (1984). The effects of exchange rate variability on output and employment. International Finance Discussion Papers, 240.

Caballero, R. J. ve Corbo, V. (1989). The effect of real exchange rate uncertainty on exports: empirical evidence. The World Bank Economic Review, 3(2), 263-278.

Clark, P. B. (1973). Uncertainty, exchange risk, and the level of international trade. Economic Inquiry, 11(3), 302-313.

De Grauwe, P. (1992). The benefits of a common currency. The economics of monetary integration. (Ed: P. De Grauwe). New York: Oxford University Press.

Dellas, H. ve Zilberfarb, B. Z. (1993). Real exchange rate volatility and international trade: A reexamination of the theory. Southern Economic Journal, 59(4), 641-647.

Dixit, A. (1989). Entry and exit decisions under uncertainty. Journal of Political Economy, 97(3), 620-638.

Doğanlar, M. (2002). Estimating the impact of exchange rate volatility on exports: evidence from Asian countries. Applied Economics Letters, 9, 859-863.

Doğru, B ve Uysal, M. (2013). Efektif euro kurundaki belirsizliğin euro bölgesi ihracatına etkisi. Atatürk Üniversitesi İktisadi ve İdari Bilimler Dergisi, 27(3), 245-262.

Franke, G. (1991). Exchange rate volatility and international trading strategy. Journal of International Money and Finance, 10(2), 292-307.

Gros, D. (1987). Exchange rate variability and foreign trade in the presence of adjustment costs. Département des Sciences Economiques, Université Catholique de Louvain Working Paper, 8704.

Hausman, J. A. (1978). Specification tests in econometrics. Econometrica, 46(6), 1251-1271. 
Kasman, A. ve Kasman S. (2005). Exchange rate uncertainty in Turkey and its impact on export volume. METU Studies in Development, 32 (June), 41-58.

Köse, N.; Ay, A. ve Topallı, N. (2008). Döviz kuru oynaklığının ihracata etkisi: Türkiye örneği (19952008). Gazi Üniversitesi İktisadi ve İdari Bilimler Fakültesi Dergisi, 10(2), 25-45.

Krugman, P. R. (1989). Exchange-rate instability. Cambridge, Massachusetts: The MIT Press.

Lee, J. ve Yi, B. C. (2005). Industry level real effective exchange rates for Korea. The Bank of Korea Institute for Monetary and Economic Research.

Levin, A.; Lin, C. F. ve Chu, C. S. J. (2002). Unit root tests in panel data: asymptotic and finite-sample properties. Journal of Econometrics, 108(1), 1-24.

McDonald, R. L. ve Siegel, D. (1986). The value of waiting to invest. Quarterly Journal of Economics, 101(4), 707-727.

Öztürk, İ. ve Acaravcı, A. (2002). Döviz kurundaki değişkenliğin Türkiye ihracatı üzerine etkisi: ampirik bir çalışma. Review of Social, Economic and Business Studies, 2, 197-206.
Öztürk, İ. ve Kalyoncu, H. (2009). Exchange rate volatility and trade: an empirical investigation from cross-country comparison. African Development Review, 21(3), 499-513.

Saatçioğlu, C. ve Karaca, O. (2004). Döviz kuru belirsizliğinin ihracata etkisi: Türkiye örneği. Doğuş Üniversitesi Dergisi, 5(2), 183-195.

Saygill, H.; Yllmaz, G.; Filazioğlu, S. ve Toprak, H. (2012). Sektörel reel efektif döviz kurları: Türkiye uygulaması. TCMB Çalışma Tebliği, 12/13.

Sercu, P. (1992). Exchange risk, exposure, and the option to trade. Journal of International Money and Finance, 11(6), 579-593.

Tarı, R. ve Yıldırım, D. Ç. (2009). Döviz kuru belirsizliğinin ihracata etkisi: Türkiye için bir uygulama. Yönetim ve Ekonomi, 16(2), 95-105.

Vergil, H. (2002). Exchange rate volatility in Turkey and its effect on trade flows. Journal of Economic and Social Research, 4(1), 83-99.

Viaene, J. M. ve de Vries, C. G. (1992). International trade and exchange rate volatility. European Economic Review, 36(6), 1311-1321. 